\title{
TESTING FOR BIASES IN SELECTION ON AVIAN REPRODUCTIVE \\ TRAITS AND PARTITIONING DIRECT AND INDIRECT SELECTION USING QUANTITATIVE GENETIC MODELS
}

Short title: Selection in a wild population is real, not apparent

Authors: Thomas E. Reed ${ }^{1 \dagger}$, Phillip Gienapp ${ }^{2 \dagger}$, Marcel E. Visser ${ }^{2}$

\section{Affiliations:}

${ }^{1}$ School of Biological, Earth \& Environmental Sciences, University College Cork, Cork, Ireland, treed@ucc.ie

${ }^{2}$ Department of Animal Ecology, Netherlands Institute of Ecology (NIOO-KNAW), P.O.

Box 50, 6700 AB Wageningen, The Netherlands. p.gienapp@ nioo.knaw.nl,

m.visser@nioo.knaw.nl

Correspondence to: Thomas E. Reed, School of Biological Earth \& Environmental Sciences,

Distillery Fields, North Mall, University College Cork, Cork, Ireland, treed@ucc.ie

$\dagger$ Joint first authorship

Keywords: phenology, climate change, microevolution, heritability, genetic correlation,

fitness

Type of article: Original article

Word count: 7450 words; References: 54; 4 Figures; 2 Tables; 1 Appendix, 1 supplementary figure and 4 supplementary tables.

This article has been accepted for publication and undergone full peer review but has not been through the copyediting, typesetting, pagination and proofreading process, which may lead to differences between this version and the Version of Record. Please cite this article as doi: 10.1111/evo.13017.

This article is protected by copyright. All rights reserved. 
Data will be archived upon manuscript acceptance in a data repository.

\begin{abstract}
:
Key life history traits such as breeding time and clutch size are frequently both heritable and under directional selection, yet many studies fail to document micro-evolutionary responses. One general explanation is that selection estimates are biased by the omission of correlated traits that have causal effects on fitness, but few valid tests of this exist. Here we show, using a quantitative genetic framework and six decades of life-history data on two free-living populations of great tits Parus major, that selection estimates for egg-laying date and clutch size are relatively unbiased. Predicted responses to selection based on the Robertson-Price Identity were similar to those based on the multivariate breeder's equation, indicating that unmeasured covarying traits were not missing from the analysis. Changing patterns of phenotypic selection on these traits (for laying date, linked to climate change) therefore reflect changing selection on breeding values, and genetic constraints appear not to limit their independent evolution. Quantitative genetic analysis of correlational data from pedigreed populations can be a valuable complement to experimental approaches to help identify whether apparent associations between traits and fitness are biased by missing traits, and to parse the roles of direct versus indirect selection across a range of environments.
\end{abstract}

\title{
Introduction
}


Determining the potential for microevolution is fundamental to assessing how populations may adapt to climate change (Holt 1990; Visser 2008) and the likelihood of evolutionary rescue in altered environments (Gomulkiewicz and Holt 1995; Carlson et al. 2014). Adaptive evolution requires heritable variation and while studies of natural populations typically find substantial genetic variation in traits under directional selection, observations of 'evolutionary stasis', i.e. a lack of selection response in heritable traits, are common (Merilä et al. 2001; Estes and Arnold 2007; Walsh and Blows 2009). One prominent hypothesis to explain such stasis, or to explain discrepancies between observed and expected evolutionary responses in general, is that selection estimates may be biased by missing traits or variables that are correlated with both focal traits and fitness (Schluter et al. 1991; Rausher 1992; Kruuk et al. 2001, 2002, 2003; Hadfield 2008; Stinchombe et al., 2002; 2014; Morrissey et al. 2010). This can be the case, for example, when the relationship between fitness and traits is environmentally-inflated and hence we would expect weaker (or no) response to selection (Fisher 1958; Price et al. 1988).

A classic example of evolutionary stasis (potentially underpinned by environmental correlations between trait and fitness) is seasonal timing of breeding in temperate birds (Price et al. 1988): early breeders generally have higher reproductive success than late breeders (Verhulst and Nilsson 2008) and egg-laying dates are typically heritable (Charmantier and Gienapp 2014), implying that earlier egg-laying should evolve. Using a quantitative genetic model, Price et al. (1988) showed how a lack of microevolution of heritable breeding time can be compatible with selection for earlier breeding, if both breeding time and fitness are influenced by a purely environmental variable, nutritional status in their example. Birds in good nutritional condition may both breed earlier and produce more surviving offspring, but earlier egg-laying will not evolve if fitness differences are entirely driven by nutritional 
status. If traits or environments that are correlated with both focal traits and fitness are missing from selection analyses, then the regression coefficients of relative fitness on trait at the genetic and environmental levels will not be the same and hence phenotypic estimates of selection will be biased (Rausher 1992; Hadfield 2008; Morrissey et al. 2010).

Several studies of plant (e.g. Stinchcombe et al. 2002; Morrissey et al. 2010) and animal (e.g. Kruuk et al. 2001, 2002; Gienapp et al. 2006) populations have sought to test whether environmentally-induced covariances between traits and fitness bias selection estimates. 'Environmentally-induced covariance' here refers to situations where the focal trait is correlated with another variable (e.g. a largely non-heritable trait such as nutritional status) that has a causal effect on fitness, and should not be confused with the process of ecological selection itself, whereby the selective environment causes a covariance between trait and fitness (MacColl 2011; Bouwhuis et al. 2015). In these studies of potential environmental biases to selection, fitness was regressed on predicted breeding values (PBVs, estimates of the net effects of an individual's genes on its phenotype relative to the population mean) for the trait of interest. Such a two-step approach is no longer considered appropriate on statistical grounds, however, as PBVs remain confounded with environmental effects on the phenotype (Postma 2006) and hypothesis tests based on PBVs can be highly anticonservative (Hadfield et al. 2010). Hence, we still have limited evidence whether selection estimates in general in nature are biased by environmental covariances between trait and fitness (or by unmeasured genetically correlated traits), particularly in free-living animal populations (work on plants indicates such biases may be substantial, Scheiner et al. 2000; Stinchcombe et al. 2002). This lack of evidence is particularly apparent for the case of changing phenotypic selection: only one study of mammals (Robinson et al. 2008), to the best of our knowledge, has tested whether changes in phenotypic selection are reflected by 
changes in selection on underlying breeding values. This is particularly relevant in the context of broad-scale environmental changes such as those wrought by global warming: changing environmental covariances between traits and fitness could give the impression that natural selection is intensifying, when in fact the genetic relationship between traits and fitness may remain unchanged, leading to erroneous predictions of evolutionary responses.

Here we test the extent to which phenotypic selection estimates for two key avian life-history traits (egg-laying date, $L D$ and clutch size, $C S$ ) may be affected by such biases, using six decades of data from two Dutch study populations of great tits (Parus major Linnaeus, 1758). Our approach is based on the logic of the secondary theorem of natural selection (STS, also known as the Robertson-Price Identity), which states that the expected per-generation evolutionary response (or 'genetic selection differential') equals the covariance between relative fitness and the breeding value for a trait, which under a simple quantitative genetic model corresponds to the additive genetic covariance between relative fitness and trait (Robertson 1966; Price 1970; Crow and Nagylaki 1976). The multivariate breeder's equation (MVBE) can also be used to predict joint responses to selection on two or more correlated traits (Lande and Arnold 1983) and has the advantage over the STS approach that direct and indirect components of selection (and selection responses) can be distinguished using selection gradients (Stinchcombe et al. 2014). However, selection gradients only partition direct and indirect selection accurately when all correlated traits affecting fitness are included in the analysis (Lande and Arnold 1983; Stinchcombe et al. 2014). Thus the MVBE can give inaccurate predictions of microevolution when correlated traits are not measured and Morrissey et al. (2010) have advocated using the STS to avoid this problem (see also Morrissey et al. 2012). More recently, Stinchcombe et al. (2014) have championed a combined approach that blends the merits of the STS and MVBE and allows evolutionary 
responses to be estimated directly without bias, as well as direct and indirect components of selection and selection responses to be partitioned. Implementation in a Bayesian-MCMC framework also allows for statistically robust estimates of uncertainty on all parameters to be made in a single model (Stinchcombe et al. 2014).

Following the approach recommended by Stinchcombe et al. (2014), we implement trivariate Bayesian-MCMC animal models involving three traits: $L D, C S$ and annual reproductive success $(A R S$, the number of recruiting offspring produced by an individual each breeding season, a proxy for reproductive fitness). Posterior distributions of the (co)variance components were then used to derive estimates of genetic selection gradients $\left(\beta_{G}\right)$, i.e. regression coefficients of breeding values for $A R S$ on breeding values for each trait. Similarly, we quantified the relationship between environmental effects on fitness and environmental effects on traits, denoted $\beta_{E}$. The difference between $\beta_{G}$ and $\beta_{E}$ then provides a measure of the extent of environmental bias to phenotypic selection (Rausher 1992; Hadfield 2008). We predicted that $\beta_{E}$ should be negative for $L D$, as females experiencing favourable environments (e.g. good nutrition) are likely to both initiate egg-laying earlier (i.e. more negative $L D$ ) and raise more young, independent of their breeding values for $L D$. For $C S$ we predicted that $\beta_{E}$ should be positive, given that females in good condition are likely to both lay more eggs and recruit more offspring, regardless of their breeding values for $C S$. While experimental manipulations of phenotypes provide the most robust tests for causal effects on fitness, such experiments can be logistically challenging in the wild and are typically attempted in only a limited number of years or environments (see Discussion for avian examples involving laying date and clutch size and associated problems).

The trivariate animal models also allow us to assess the relative contributions of direct versus indirect genotypic selection on each trait - the latter mediated via a potential genetic 
correlation between $L D$ and $C S$. Previous studies have provided mixed evidence for such a correlation; for example, Sheldon et al. (2003) reported a negative genetic correlation for a Swedish population of collared flycatchers (Ficedula albicollis), as did Garant et al. (2008) for a UK population of great tits. Husby et al. (2010) reported a negative genetic correlation in one great tit population, but a positive (albeit non-significant) genetic correlation in another. To test whether changing patterns of phenotypic selection (in the case of $L D$, related to climate change and phenological mismatch; Visser et al. 1998, 2006; Reed et al. 2013) provide a reliable guide to changing selection on underlying breeding values, we split years into groups based on variation in phenotypic selection and compared $\beta_{G}$ against $\beta_{E}$ in each case. Finally, net responses to selection on each trait for both the full and sub-sampled datasets were estimated using both the STS and MVBE approaches. By comparing them, one can assess the extent to which missing correlated traits may bias predictions of microevolution (Morrissey et al. 2012).

\section{Materials and Methods}

Data

The great tit populations in the $\mathrm{HV}\left(52^{\circ} 23^{\prime} \mathrm{N}, 05^{\circ} 51^{\prime} \mathrm{E}\right.$, central Netherlands) and on Vlieland $\left(53^{\circ} 10^{\prime} \mathrm{N}, 05^{\circ} 02^{\prime} \mathrm{E}\right.$, one of the West Frisian Islands in the Wadden Sea) have been continuously monitored since 1955. Here we consider brood years from 1955 to 2013 inclusive, with recruit data from 2014 being used to estimate selection on traits expressed in 2013 (thus 60 years of data were used in total). Nest boxes are supplied in excess in all suitable habitats in both study areas. The laying date of the first egg of a clutch $(L D)$ was calculated from the number of eggs found during weekly nest box checks, assuming that one egg is laid per day. Clutch size $(C S)$ was defined as the maximum number of eggs found 
before or during incubation. Adults were caught during chick feeding and identified by their aluminium and colour rings, or ringed if not previously caught. All nestlings were ringed with aluminium rings before fledging. Annual reproductive success $(A R S)$ was defined as the number of recruits, i.e. the number of offspring that returned as adults to breed in our study population, produced by that female in a given breeding season (including recruits from potential second clutches, as decisions regarding the timing or size of first clutches will affect the total number of recruits, not just those from first broods).

During the study period a number of broods was manipulated, e.g. by supplying food or manipulating clutch or brood size. Since these manipulations could affect offspring survival, manipulated broods were excluded from all analyses. From 1996 to 2003 a clutch size selection experiment was carried out in the Vlieland study population (Postma et al. 2007). During this experiment a large proportion of clutches was removed or swapped but because all these clutches were excluded from our analyses, this experiment would not affect our analyses here (in total, eight full years of data were excluded for VE due to manipulations: $1955-57,1961-62,1967-68,2012)$. We restricted our analyses to the Eastern subpopulation on Vlieland as the pedigree for the Western subpopulation is considerably shallower due to higher immigration from the mainland (Postma \& van Noordwijk 2005). Full details on sample sizes are provided in Table 1.

\section{Statistical models}

Our focal traits, $L D$ and $C S$, are determined by the female and unaffected by properties of the male in great tits (Caro et al. 2009). We consequently modelled these traits to be sex-limited, i.e. not expressed by males, but not genetically sex-linked, which means that males were not assigned any phenotypes but paternal links were included in the pedigree. We analysed 
genetic (co)variances of $L D, C S$ and $A R S$ using the so-called 'animal model' (Henderson 1950; Kruuk 2004; Wilson et al. 2010) implemented in a Bayesian framework. Animal models allow genetic and environmental sources of trait (co)variation to be disentangled, and as such are well suited for quantitative genetic analyses in pedigreed natural populations as they use all information about relatedness among individuals, and can handle unbalanced datasets. Key advantages of the Bayesian approach, which utilises Markov Chain Monte Carlo (MCMC) techniques (Hadfield 2010), are that (1) all sources of variability and uncertainty are accounted for in the estimation procedure, which produces full posterior probability distributions, rather than point estimates and approximate standard errors, of parameters of interest and (2) non-Gaussian trait distributions can be modelled more easily and reliably than in frequentist approaches (Morrissey et al. 2014).

Since many females bred in multiple years, we included a permanent environment random effect in all models and also a maternal effect. All three traits vary considerably among years due to phenotypically plastic responses, e.g. to temperature $(L D)$, population density $(C S)$ or winter conditions $(A R S)$. To account for these plastic year-to-year variations, $L D$ and $C S$ were mean- and variance-standardised within years and we included a fixed effect of year for $A R S$ in all models (standardising $A R S$ within years was avoided as it was more appropriate to treat this as a Poisson variable in the models, which requires integer values). First-time breeders generally have a later $L D$, lay smaller clutches and have reduced reproductive success and we hence included age (factor with two levels: 'second calendar-year' (=first time breeder) and 'older') as a fixed effect in all models.

The R-package MCMCglmm (Hadfield 2010) was used to run all animal models. Uninformative, proper priors were used with an $3 \times 3$ identity matrix for $\mathrm{V}$ and $\mathrm{nu}=1.002$. The results were robust to alternative prior specifications (e.g. stronger priors, results not 
shown). We used a burn-in period of 250,000 for all models and a thinning interval of 10,000 to ensure proper mixing of the chain and independent samples (the autocorrelation between samples was always $<0.2$ ). The number of effective samples was never substantially smaller than the number of samples drawn (200).

Decomposing selection into genetic versus environmental components.

Selection is technically measured as the relationship between trait and relative fitness (individual fitness divided by mean individual fitness), which can be expressed as a regression slope, as in selection gradients (Lande and Arnold 1983), or as a covariance, as in selection differentials (Price 1970; Endler 1986). However, relative fitness does not conform to any known parametric distribution and hence we instead modelled the (genetic and environmental) relationships between trait and absolute $A R S$ using a log-link generalised linear model (Poisson distributed errors). The regression coefficients from this type of model are then equivalent to the Lande-Arnold regression coefficients using relative fitness (Smouse et al., 1999).

With two traits of interest $(Z 1$ and $Z 2)$ and a single fitness measure $(W)$, one can fit a trivariate animal model that produces as output a $3 \times 3$ genetic covariance matrix, which following Stinchcombe et al. (2014) we call $\mathbf{G}_{\mathbf{z w}}$ :

$$
\boldsymbol{G}_{\mathbf{z} \boldsymbol{w}}=\left[\begin{array}{ccc}
V g_{z 1} & \operatorname{cov}_{z 1, z 2} & \operatorname{cov}_{z 1, w} \\
& V g_{z 2} & \operatorname{cov}_{z 2, w} \\
& & V g_{W}
\end{array}\right]
$$

Note that while use a g subscript here and throughout the paper when referring to genetic parameters, these actually refer to the variance or covariance of additive genetic effects (i.e. breeding values). $V g_{W}$ corresponds to the genetic variance in the fitness component (if total 
relative fitness were used, this parameter would specify the upper limit on the rate of evolution, according to Fisher's fundamental theorem, Fisher 1930). The off-diagonal matrix elements of the column/row corresponding to fitness indicate genetic covariances between traits and fitness; arranged as a vector these give $\mathbf{s}_{\mathbf{G}}$, the genetic selection differentials (Stinchcombe et al. 2014). These correspond to the predicted evolutionary responses for each trait, according to the STS (with the caveat that here we only consider a component of fitness, $A R S$, as opposed to total fitness). Matrix elements not involving $W$ represent the standard genetic covariance matrix $\mathbf{G}$ for the traits (in this case a $2 \times 2$ matrix). Structurally identical $3 \times 3$ covariance matrices are produced for all random effects included in the animal models. The vector of genetic selection gradients $\boldsymbol{\beta}_{\boldsymbol{G}}$ can then be derived using $\boldsymbol{\beta}_{\boldsymbol{G}}=\mathbf{G}^{-\mathbf{1}} \mathbf{S}_{\mathbf{G}}$ (Lande and Arnold 1983; Rausher 1992; Stinchcombe et al. 2014). Likewise, we estimated the overall relationships between each trait and $A R S$ at the environmental level as $\boldsymbol{\beta}_{\boldsymbol{E}}=\mathbf{E}^{-\mathbf{1}} \mathbf{S}_{\mathbf{E}}$, where $\boldsymbol{\beta}_{\boldsymbol{E}}$ was a vector of environmental "selection" gradients, $\mathbf{E}$ was an environmental covariance matrix calculated by summing the posterior distributions of the covariance matrices for the permanent environment effects (repeatable differences among individuals across years not due to additive genetic effects), maternal effects, and residual deviations (within year environmental effects on phenotype). $\mathbf{s}_{\mathbf{E}}$ refers to the vector of environmental selection differentials, calculated by summing the permanent environment, maternal and residual covariances between trait and fitness. The estimates of $\boldsymbol{\beta}_{\boldsymbol{E}}$ were very similar when maternal effects (which could themselves contain a maternal genetic component) were excluded from the calculations. We also re-ran the trivariate animal models (all years considered together only) using unstandardised trait values and including year effects in the calculation of $\boldsymbol{\beta}_{\boldsymbol{E}}$ in order to explore whether the main conclusions were affected by our procedure of standardising traits within years (see Appendix 1). 
The environmental bias to phenotypic selection on each trait was then quantified as $\boldsymbol{\beta}_{\boldsymbol{E}}-\boldsymbol{\beta}_{\boldsymbol{G}}$ (bold symbols are used to denote the $2 \times 1$ vector of biases, with the first element corresponding to the bias for $L D$ and the second the bias for $C S$; when referring to the bias for each trait separately we simply use $\beta_{E}-\beta_{G}$; see Fig.1 for a graphical representation of environmental biases to selection). Statistical support for an environmental bias to selection on either trait was then assessed by simply checking whether the posterior distributions of this metric overlapped zero. If the 95\% HPD (highest posterior density) interval included zero, then the null hypothesis of no environmental bias was accepted.

Changes in selection through time: real or apparent?

To test whether changes in the magnitude of phenotypic selection were underpinned by similar changes in selection on breeding values, we split the Hoge Veluwe (HV) and Vlieland East (VE) datasets into years with 'strong', 'medium' and 'weak' phenotypic selection on $L D$, and also (separately) based on 'strong', 'medium' and 'weak' phenotypic selection on CS. Annual standardised phenotypic selection differentials (denoted $s_{P}$ ) were calculated by dividing individual fitness by annual mean fitness and regressing this relative individual fitness against (mean and variance) standardised egg-laying date or clutch size (Lande and Arnold 1983). We then split years into three groups based on thirds on the distribution of $s_{P}$, for each trait (see Table 1for full details). The 'weak' and 'strong' categories not only differed in strength but also partly in the direction of selection. The 'weak' category contained years with weakly positive $(L D)$ or negative to no selection $(C S)$, the 'medium' category years with no or weakly negative $(L D)$ or positive $(C S)$ selection, while the 'strong' category contained years with strongly negative $(L D)$ or strongly positive $(C S)$ selection (Table 1). 
Trivariate animal models were fitted for each group of years and $\beta_{G}$ and $\beta_{E}$ were calculated as before. The statistical significance of directional selection on underlying genotypes was determined qualitatively by assessing whether the HPD interval of $\beta_{G}$ overlapped zero for each trait/phenotypic selection strength combination. Similarly, support for environmental biases to phenotypic selection in each category was determined by assessing whether the HPD interval of $\beta_{E}-\beta_{G}$ did not overlap zero (see Fig.1 for a hypothetical example). Due to the large data sets necessary to reliably estimate genetic covariances it was simply impossible to conduct this analysis at a finer temporal scale, let alone at an annual basis.

Assessing the power to detect environmental biases

Even if the HPD interval of our metric of bias $\left(\beta_{E}-\beta_{G}\right)$ includes zero, the possibility remains that insufficient statistical power was available to detect true biases (e.g. relatively small biases). To get a better sense for this we undertook a power analysis, whereby two traits were simulated (assuming multivariate normality for simplicity) to be uncorrelated at the genetic level, but correlated at the environmental level. One of the 'traits' was assumed to be fitness and the other either $L D$ or $C S$; thus the simulations modelled a real (and complete) environmental bias to phenotypic selection. Uncorrelated breeding values for each trait were simulated using the $r b v$ function in MCMCglmm (Hadfield 2010) across both the HV and VE pedigrees for the same number of individuals for which actual phenotypic information was available. Correlated environmental deviations were then simulated from a multivariate normal distribution and added to the uncorrelated breeding values to generate simulated phenotypes. Permanent environment and maternal effects were ignored for simplicity. Bivariate animal models were then run on these simulated phenotypes to generate estimates of $\beta_{G}$ and $\beta_{E}$ as above. Six different strengths of environmental bias (i.e. six different $\beta_{E}$ 
values, and therefore also $\beta_{E}-\beta_{G}$ values, given that $\beta_{G}$ was simulated to be zero) ranging from 0 to 0.50 were simulated. For each, 500 replicate simulations were run for both $\mathrm{HV}$ and VE and power was calculated as the proportion of simulations where the HPD interval of the resulting posterior estimates of $\beta_{E}-\beta_{G}$ did not include 0 .

Comparing evolutionary predictions of the STS and MVBE

Estimates of the response to selection on $L D$ and $C S$ were obtained from the trivariate animal models by extracting the posterior distributions of $\mathbf{S}_{\mathbf{G}}$ (i.e. the additive genetic covariances between each trait and $A R S$ ), which corresponded to the evolutionary predictions based on the STS approach. Estimates based on the MVBE approach were obtained using $\Delta \overline{\boldsymbol{z}}=\boldsymbol{G} \boldsymbol{\beta}$, where $\Delta \overline{\boldsymbol{Z}}$ indicates the change in the mean of each trait, $\boldsymbol{G}$ is the genetic covariance matrix as estimated from the trivariate model (the upper $2 \times 2$ quadrant of $\boldsymbol{G}_{\boldsymbol{z} \boldsymbol{w}}$, see above) and $\boldsymbol{\beta}$ is the vector of phenotypic selection gradients, as estimated from the posterior distributions of the trivariate animal model (using $\boldsymbol{\beta}=\boldsymbol{P}^{-\mathbf{1}} \boldsymbol{s}_{\boldsymbol{P}}$, where $\boldsymbol{P}=\boldsymbol{G}+\boldsymbol{E}$ and $\boldsymbol{s}_{\boldsymbol{P}}=\boldsymbol{s}_{\boldsymbol{G}}+\boldsymbol{s}_{\boldsymbol{E}}$ ). The goal of this exercise was to compare predictions from the STS and MVBE relative to each other, rather than to generate quantitatively accurate predictions of selection responses per se - the latter would not be completely reliable in any case, given that assumptions of both the STS and MVBE such as constant demography and non-overlapping generations are not met. The predicted responses to selection based on both approaches were in phenotypic standard deviation (PSD) units for each trait, because standardised trait values were used in both cases.

\section{Results}

Phenotypic patterns 
Estimates of directional selection at the phenotypic level varied substantially among years in strength and sign for both $L D$ and $C S$ in each population (Supplementary Fig.1). For the HV population, earlier layers had higher fitness on average across all years (mean $s_{P}:=-0.14$, range among years $=-1.06$ to 0.98$)$, with 45 out of 59 years $(76 \%)$ exhibiting negative selection differentials. Phenotypic selection for earlier laying was on average weaker across all years for the VE population (mean $s_{P}:=-0.014$, range among years $=-0.86$ to 0.64 ), with 28 of 52 years (54\%) exhibiting negative selection differentials. In the HV population, females laying larger clutches had higher fitness on average across all years (mean $s_{P}:=0.14$, range among years $=-0.68$ to 0.69$)$, with 40 of 59 years $(68 \%)$ exhibiting positive selection differentials, whereas in the VE population phenotypic selection on $C S$ was on average weaker $\left(\right.$ mean $s_{P}:=0.02$, range among years $=-0.72$ to 0.48$)$, with 32 of 44 years $(73 \%)$ exhibiting positive selection differentials.

$L D$ and $C S$ were negatively phenotypically correlated (HV population all years: standardised trait values: $r_{p}=-0.23$; unstandardised trait values: $r_{p}=-0.21$; VE population all years: standardised trait values: $r_{p}=-0.12$; unstandardised trait values: $r_{p}=-0.06$; all $\left.P<0.05\right)$. These reflected within-year associations between $L D$ and $C S$, as the annual means were not significantly correlated for either population (HV population: $r=-0.10, P=0.45$; VE population: $r=0.10, P=0.46)$. For the $\mathrm{HV}$ population, there was a trend towards earlier egglaying (across all years) of 0.1 days per year $\left(b=-0.10 \pm 0.04, t_{1,57}=-2.47, P=0.016\right)$ and also a trend towards smaller first clutches $\left(b=-0.02 \pm 0.006, t_{1,57}=-2.44, P=0.018\right)$ (Supplementary Fig.1). For the VE population, there were no significant temporal trends in either $L D\left(b=-0.08 \pm 0.04, t_{1,52}=-1.81, P=0.076\right)$ or $C S\left(b=-0.01 \pm 0.01, t_{1,52}=-1.21, P=\right.$ 0.27) (Supplementary Fig.1). 
Trivariate animal models: all years considered together

Additive genetic variance was found to be non-zero for all three traits in both populations (see Supplementary Tables for full results of trivariate models). For the HV population, the heritability $\left(h^{2}\right)$ of standardised $L D$ was estimated at 0.16 (HPD interval: $0.09-0.20$; the point estimate here and for all subsequently reported parameters refers to the posterior mode, and the range to the HPD interval), $h^{2}$ of standardised $C S$ was estimated at $0.21(0.14-0.30)$ and the $h^{2}$ of (unstandardised) ARS was estimated at $0.29(0.15-0.38)$. For the VE population, the heritability $\left(h^{2}\right)$ of standardised $L D$ was estimated at 0.17 (HPD interval: 0.12 - 0.29), $h^{2}$ of standardised $C S$ was estimated at $0.18(0.13-0.27)$ and the $h^{2}$ of (unstandardised) $A R S$ was estimated at $0.24(0.16-0.36) . L D$ and $C S$ were standardised within years, while a fixed effect of year was included for $A R S$, and thus the $h^{2}$ estimates here correspond to the fraction of within-year variation (additive genetic + permanent environment + maternal + residual) explained by additive genetic effects. For $A R S$, the $h^{2}$ estimate is at the scale of the linear predictor. For purposes of comparison with other traits, we backtransformed this estimate to the observed scale $\left(h^{2}\right.$ obs $)$ using the following equation (Foulley 1993): $h_{o b s}^{2}=\frac{\mu^{2} \sigma_{a}^{2}}{\mu+\mu^{2}\left[\exp \left(\sigma_{a}^{2}\right)-1\right]}$, where $\mu$ was the mean on the observed scale and $\sigma_{a}^{2}$ was the additive genetic variance estimated by the model. This gave an estimate of $h^{2}$ obs for ARS of $0.05(0.03-0.07)$ for the HV population and $0.05(0.03-0.07)$ for the VE population.

Considering all years together, $\beta_{G}$ for $L D$ was estimated as $-0.08(-0.31-0.26)$ for the HV population, while $\beta_{E}$ was estimated at -0.20 (-0.24--0.06; Table 2$)$. The negative relationship between $L D$ and $A R S$ at the environmental level was driven predominantly by a statistically significant (HPD interval not overlapping zero) negative residual covariance (Supplementary Table 4), as the permanent environment (Supplementary Table 2) and maternal covariances (Supplementary Table 3) were overlapping zero. The bias statistic $\left(\beta_{E}-\right.$ 
$\left.\beta_{G}\right)$ for $L D$ was estimated as $-0.03(-0.46-0.21$, Table 2 , Fig. 2$)$; note that the posterior mode of the derived statistic $\beta_{E}-\beta_{G}$ can deviate from the difference in the posterior modes of $\beta_{E}$ and $\beta_{G}$ due to posterior distributions not being perfectly symmetrical.

Considering all years together, $\beta_{G}$ for $C S$ was estimated as $0.06(-0.15-0.33)$ for the HV population, while $\beta_{E}$ was estimated at $0.09(0.04-0.21$; Table 2$)$. The positive relationship between $C S$ and $A R S$ at the environmental level was driven predominantly by a statistically significant positive residual covariance (Supplementary Tables). The bias statistic $\left(\beta_{E}-\beta_{G}\right)$ for $C S$ was estimated as 0.01 (-0.24-0.32, Table 2, Fig. 2).

For the VE population, $\beta_{G}$ for $L D$ was estimated as -0.06 (CI: $-0.26-0.12$ ) considering all years together, while $\beta_{E}$ was estimated at 0.01 (-0.07-0.05; Table 2). Surprisingly, a positive permanent environment covariance between $L D$ and $A R S$ was evident across all years for the VE population (Supplementary Table 2), whereas a negative residual covariance was found (Supplementary Table 4). These counteracting covariances explain why the overall $\beta_{E}$ was close to zero. The bias statistic $\left(\beta_{E}-\beta_{G}\right)$ for $L D$ was estimated as $-0.01(-0.20-0.24$, Table 2 , Fig. 2).

For the VE population, $\beta_{G}$ for $C S$ was estimated as $-0.02(-0.17-0.19)$ considering all years together, while $\beta_{E}$ was estimated at $0.08(0.01-0.12$; Table 2$)$. The positive relationship between $C S$ and $A R S$ at the environmental level was driven predominantly by a positive residual covariance (Supplementary Tables). The bias statistic $\left(\beta_{E}-\beta_{G}\right)$ for $C S$ was estimated as $0.11(-0.14-0.27$, Table 2, Fig. 2). The trivariate animals based on unstandardised trait values produced very similar results to those based on standardised $L D$ and $C S$ (Appendix 1).

Trivariate animal models: splitting years by selection strength categories 
For both populations, changes in phenotypic selection strength for both traits were generally paralleled by similar changes in selection on the additive genetic component of trait variation (Fig. 2, Table 2). The 'strong' phenotypic selection category for CS in the HV population was the only one where the HPD intervals for $\beta_{G}$ were completely non-overlapping zero (Fig.2, Table 2), indicating that selection on $C S$ breeding values was consistently positive in these years. In general, however, the model estimates for $\beta_{G}$ became larger in absolute terms (more positive for $C S$ and more negative for $L D$ ) as phenotypic selection became stronger. Although the posterior modes for $\beta_{G}$ deviated somewhat from those for $\beta_{E}$ (Fig.1), the full posterior distributions overlapped considerably and the HPD intervals for $\beta_{E}-\beta_{G}$ overlapped zero in all cases (Table 2). Full details on the additive genetic, permanent environment, maternal and residual covariance matrices for each population/trait/ selection strength category combination are given in Supplementary Tables 1-4.

Power to detect environmental biases

The power analyses showed that there was $>80 \%$ power to detect true environmental biases to selection of approximately $0.40\left(\beta_{E}-\beta_{G}\right)$ or higher for both populations, but only approximately $25-50 \%$ power to detect environmental biases of 0.20 to 0.30 (Fig. 3). Power declined approximately sigmoidally as simulated $\beta_{E}-\beta_{G}$ decreased. Power to detect biases was slightly higher for the VE population, likely reflecting the better pedigree (more relatedness links) compared to the HV pedigree.

Comparing evolutionary predictions of the STS and MVBE 
For $L D$, the MVBE predicted a very small response to selection $(\Delta z=-0.02$ PSD or 0.09 days, per generation) overall across the whole time period in the HV population, whereas the STS predicted a smaller response to selection $\left(\mathrm{s}_{\mathrm{g}}=-0.003\right.$ PSD, HPD interval: $\left.-0.053-0.031\right)$. Similarly, for the VE population, a very weak response to selection was predicted (error bars overlapping zero for both methods) by both the MVBE and the STS (Fig.4). These responses refer to the expected net rate of microevolution per generation, assuming constant directional selection. For $C S$, the MVBE predicted a very small positive response to selection $(\Delta z=$ 0.025 PSD, or 0.05 eggs, per generation) overall across the whole time period in the HV population. The modal estimate of the response to selection according to the STS was similar $\left(\mathrm{s}_{\mathrm{g}}=0.035\right.$ PSD) but with a broader HPD interval that overlapped zero $(-0.020-0.078$ PSD). For the VE population, a slightly positive response to selection was predicted by the MVBE $(\Delta z=0.011 \mathrm{PSD}$, or 0.020 eggs per generation) across all years, while the STS predicted a slightly negative response (-0.003 PD) but with a HPD interval (-0.034 - 0.035 PSD) that overlapped zero (Fig.4).

Predicted responses to selection were on average larger for both methods in years where phenotypic selection was stronger, and the MVBE and STS gave qualitatively and quantitatively similar predictions when years were grouped according to phenotypic selection strength (Fig.4). The uncertainty associated with the STS predictions was considerably larger than that associated with the MVBE predictions (Fig.4). The general concordance between the MVBE and STS predictions reflected the fact that the genetic covariance between $L D$ and CS overlapped zero in all trivariate animal models (Supplementary Table 1) and that no strong environmental biases to selection were found (which could have biased the MVBE, but not the STS, predictions). Thus indirect selection responses appeared not to play any role, 
at least with respect to the two traits considered in the analysis, as there was no evidence for statistically significant genetic covariance between them.

\section{Discussion}

Using six decades of individual-based life history data and advanced, powerful statistical techniques we have shown that (1) heritable variation in a key component of fitness (the annual number of recruits) exists and thus microevolution is possible in our study populations, (2) heritable variation exists for two key reproductive traits ( $L D$ and $C S$ ) known to affect fitness, and (3) selection estimates are relatively unbiased by missing traits or variables that may be correlated with these traits and fitness. This latter result is our most important finding and can be interpreted as a "quantitative genetic signature" (c.f. Morrissey and Ferguson 2011) of changing patterns of natural selection (see also Robinson et al. 2008).

Phenotypic selection estimates in our great tit study populations are therefore reliable and not entirely driven by changes in environmental correlations between traits and fitness. This does not imply that the latter do not exist ( $\beta_{E}$ for each trait was typically non-zero in the datasets analysed here, Fig.2, Table 2), nor that environmental relationships between trait and fitness are not also changing ( $\beta_{E}$ was different for different phenotypic selection strength categories in line with our predictions, i.e. it was more negative in years where $s_{P}$ for $L D$ was more negative, and more positive in years where $s_{P}$ for $C S$ was more positive, Fig.2, Table 2). Rather, changes to $\beta_{E}$ were paralleled by similar changes to $\beta_{G}$ (Fig.2), which implies that our phenotypic selection estimates were not unduly biased. Directional environmental change, for example associated with regional warming (Gienapp et al. 2013), should therefore induce evolutionarily-relevant selection. We note, however, that while equality of $\beta_{G}$ and $\beta_{E}$ for each trait is consistent with these traits causally affecting fitness, it is not sufficient: proportionality 
of the phenotypic and genetic covariance matrices for the focal and selected traits also gives rise to equality of $\beta_{G}$ and $\beta_{E}$ even when the regression coefficients do not represent the causal effect of the focal trait on fitness (see Section 2 in Appendix A of Hadfield 2008). Should covariance in year-effects on each trait should be included in the calculation of $\beta_{E}$ ? The answer is not immediately obvious and depends on the extent to which (interannual) genotype-by-environment interactions contribute to overall trait variation and whether one conceives of selection as operating within years, or also across years. In our case, including year effects in the calculation of $\beta_{E}$ tended to make the latter deviate slightly more from $\beta_{G}$ (i.e. more bias) compared to when year-effects were excluded, but the differences were relatively minor, being somewhat more pronounced for $C S$ because the year covariance was positive for that trait (Appendix 1).

If we had found a significant deviation of $\beta_{E}$ from $\beta_{G}$ in our datasets (i.e. if the posterior distributions of $\beta_{E}-\beta_{G}$ had not overlapped zero), this would have indicated that the null hypothesis of no bias to selection should have been rejected, which was not the case for any of the datasets we analysed. However, absence of evidence is not necessarily evidence of absence: a lack of significant bias could simply be explained by a lack of statistical power to detect true bias. Our power analyses indicated that we only had sufficient power to detect large biases (Fig.3), although what constitutes 'large bias' is somewhat subjective and difficult to define. According to our power analysis, we had $>80 \%$ power to detect biases in excess of approximately 0.4 , but only $25-50 \%$ power to detect 'moderate' biases in the region of 0.2 to 0.3 (which encompassed many of the actual estimates of $\beta_{E}-\beta_{G}$, see Table 2) with the units here corresponding to those for standardised selection gradients, i.e. proportional change in relative fitness per phenotypic standard deviation. Stinchcombe et al. (2002) provided an analysis of environmentally-induced biases in phenotypic selection estimates 
based on field experiments with three species of annual plants and reported standardised selection gradients at both the phenotypic $\left(\beta_{P}\right)$ and additive genetic $\left(\beta_{G}\right)$ levels. The mean absolute bias based on their data (calculated as $\left|\beta_{P}-\beta_{G}\right|$, extracting the $\beta_{P}$ and $\beta_{G}$ values from their Tables 2, 3 and 4) was 0.28 (note that with no bias, $\beta_{P}=\beta_{G}=\beta_{E}$ ) and ranged from 0.02 to 0.77. Using this as a yardstick suggests that we had sufficient power in the current study to detect only relatively large biases, but Stinchcombe et al. (2002) noted that their estimated biases were likely conservative in that they were based on data from spatially replicated field experiments; i.e. most studies of selection in the wild are based on correlational data collected under uncontrolled environmental conditions, where environmental biases may be considerably larger. In the current study, the standard deviation in $s_{P}\left(s_{P}\right.$ is equivalent to univariate $\beta_{P}$ ) for our great tit populations was 0.34 for $L D$ and 0.28 for $C S$ (pooling annual $s_{P}$ estimates from both populations). Denoting this standard deviation as $\sigma\left(s_{P}\right)$, as a rule of thumb one might consider biases between $\sigma\left(s_{P}\right)$ and $2 \sigma\left(s_{P}\right)$ as 'moderate' and biases in excess of $2 \sigma\left(s_{P}\right)$ as 'large'. Thus while we lacked sufficient statistical power to detect 'small' biases (e.g. $<\sigma\left(s_{P}\right)$ ), such minor biases would be less of a concern in the sense that inferences regarding evolutionarily relevant selection would be unlikely be too 'far off the mark' if only phenotypic-level information were available. Likewise, predictions of the response to selection based on the MVBE should not be too inaccurate (predictions based on the STS would not suffer from the same problem, as they are unbiased by potential environmental covariances or missing traits).

The STS and MVBE approaches yielded similar predicted responses to selection on each trait in each population (Fig.4). While the STS has the advantages over the MVBE that responses to selection can be estimated in a single model and are unbiased, one cannot disentangle direct from indirect components of selection/selection responses (Stinchcombe et al. 2014). 
The MVBE approach on the other hand suffers from the major disadvantage that one can only be sure that the predictions are accurate when all correlated traits under selection are included in the analysis (Stinchcombe et al. 2014). The broad concordance we found between the STS and MVBE predictions implies that missing correlated traits were not a major issue in our case. However, the uncertainty associated with both sets of predictions was substantial and thus we cannot rule out the existence of missing correlated traits completely, we can just infer that their potential absence did not unduly bias the MVBE estimates. The quantitative predictions themselves (under both approaches) must be treated with caution to some extent, however, because both the STS and MVBE make assumptions that are not entirely met by our data, such as constant demography and non-overlapping generations. Our primary goal in comparing the predictions of both approaches, however, was to assess the extent to which missing correlated traits may have been an issue, rather than to generate quantitatively accurate predictions of selection responses per se.

By applying the analytical framework recommended by Stinchcombe et al. (2014), we were able to estimate partial genetic selection gradients for each trait and therefore to separate the effects of direct versus indirect selection. The results indicated that indirect components of selection were relatively unimportant, given that the estimates for $\boldsymbol{\beta}_{\boldsymbol{G}}$ were very similar to the estimates for $\boldsymbol{s}_{\boldsymbol{G}}$. The phenotypic correlations between $L D$ and $C S$ were also relatively weak in both populations and the genetic correlations were not significantly different from zero (Supplementary Table 1), implying that selection on one trait would not cause a correlated response in the other. A positive genetic correlation in this case would imply a geneticallybased trade-off, in that the traits are typically selected in opposite directions. Studies of other songbird populations have previously reported a negative genetic correlation between these traits (Sheldon et al. 2003, Garant et al. 2008) or no genetic correlation/a positive correlation 
(Husby et al. 2010), suggesting that genetic trade-offs between these avian reproductive traits are not inevitable and may even be population- or environment-specific. Estimates of genetic covariances/correlations are typically associated with large uncertainties (Lynch and Walsh 1998) however, and comparisons of their strength across contexts must therefore be treated with caution.

Patterns of phenotypic selection on $L D$ and $C S$ differed somewhat between the HV and VE study populations, with $s_{P}$ deviating more from zero in particular for $L D$ in the HV population (Table 1, Supplementary Fig.1). In the early part of the study (1950s to early 1980s) the breeding time of great tits in the HV study area was relatively well-matched, on average, with the caterpillar food peak and hence no net directional selection for earlier egglaying was expected or observed (Visser et al. 1998; Reed et al. 2013). An increasing phenological mismatch between great tits and their food then developed from the 1980s onwards as climate change unfolded (Visser et al. 1998, 2006, Chevin et al. 2015) and as a result, phenotypic selection for earlier laying intensified (Reed et al. 2013, Supplementary Fig.1). The strong selection category for $L D$ therefore consisted of (largely, but not exclusively, more recent) years where phenological mismatch was high and this explains why $\beta_{G}$ was more negative in these (Fig. 2) and why a stronger response to selection was predicted (Fig. 4). The fact that the HPD intervals associated with $\beta_{G}$ and $s_{G}$ for $L D$ overlap zero in all selection strength categories indicates that years with varying selection pressures (not only in terms of magnitude, but potentially also sign) are still pooled in these analyses, and also that genetic signatures of directional selection are more difficult to pick out from the 'noise' when sample sizes are reduced like this. The importance of phenological matching with a shifting food peak has been less well-studied in the VE population, but it is likely that timing relative to seasonal peaks in caterpillar biomass plays a similar role in driving selection on $L D$ in that 
area. Fluctuations in population density appear to drive selection on CS (Both et al. 2000; Saether et al. In Press): under high population densities with increased competition for resources or territories, individuals in good 'condition' would have a selective advantage, which means that under high densities breeders should trade-off a larger clutch size for an increased investment in offspring, leading to selection for smaller clutch size under high densities. Climate change may also select indirectly on $C S$ via a genetic correlation with $L D$, but as we have shown, evidence for genetic linkages between these traits was lacking in this study.

On average over the six decades considered, selection appeared to favour earlier egg-laying and larger clutches in both populations and in the HV population mean $L D$ advanced significantly over time, yet mean $C S$ also exhibited an overall negative temporal trend (Supplementary Fig.1). For the VE population, both mean $L D(b=-0.16 \pm 0.06, P=0.01)$ and mean $C S(b=-0.03 \pm 0.01, P<0.001)$ exhibited significant negative temporal trends when the data were restricted to 1970 onwards (sample sizes were much smaller in the earlier years). Both patterns are likely mostly explained by phenotypic plasticity rather than microevolution. For $L D$ it is well established that earlier egg-laying occurs as a plastic response to higher spring temperatures, with springs getting progressively warmer in recent decades in the Netherlands (Visser et al. 1998; 2006; Nussey et al. 2005, Husby et al. 2010). An increase in population density may drive a decrease in mean $C S$ as a plastic response, yet population size has not exhibited a directional trend in the HV over time, although it has increased significantly in VE. Other factors such as changes in food supply or habitat may also be responsible for the observed trends in $C S$ in both populations.

Testing for biases to selection using observational versus experimental approaches 
Here we tested for potential biases to selection using very long-term datasets and an animal model approach, which had the advantage of generality in the sense that the analyses integrated across many different types of years and hence variable selective pressures, whereas experimental approaches to the same question (e.g. Stinchombe et al. 2002) typically can only be carried out in one or a few years. Nonetheless, we acknowledge that correlational data have their limits and that experimental manipulations of putative targets of selections (i.e. phenotypes of interest) provide the most robust tests of whether traits truly causally affect fitness. Such experiments are logistically challenging, however.

Several studies with birds have manipulated $L D$ and $C S$ (or brood size), and found that these manipulations affected reproductive success (e.g. Dijkstra et al. 1990; Daan et al. 1990; Verhulst and Tinbergen 1991; Brinkhof et al. 1993; Svensson 1997; Pettifor et al. 1998; Visser and Lessells 2001). Delaying breeding time by removing eggs, which were then replaced by the breeding female, reduced the reproductive success of the manipulated broods as expected (reviewed by Verhulst and Nilsson 2008). One problem with these egg-removal experiments, however, is that the manipulated females paid the cost of producing additional eggs (Visser \& Lessels 2001), which could have impaired their subsequent parental effort and thereby also their reproductive success. Other experiments advanced $L D$ by supplementary feeding (e.g. Nager et al. 1997). This manipulation, however, also affects the females' condition (and thus potentially their fitness, independently of changes in $L D$ ) and it would be difficult to conclude that $L D$ causally affects fitness from these experiments. Under the 'individual optimisation hypothesis', both reducing and enlarging $C S$ should lead to a fitness decline (Nur 1997). Experiments manipulating CS generally found this (Pettifor et al. 1998; Tinbergen and Both 1999) but the fitness decline of enlarged broods (in the case of brood size manipulations ) was often smaller than expected, which can be explained by the fact that 
these females did not incur a cost for egg-production and incubation (Visser and Lessells 2001, Monaghan and Nager 1997).

While experiments therefore hint at causal relationships with fitness for both $L D$ and $C S$, the extent of potential biases to selection estimates are more difficult to predict a priori and quantitative genetic analysis of correlational data, as we performed here, can help to clarify this. Such approaches applied to mammals (Kruuk et al. 2002; Robinson et al. 2008; Morrissey et al. 2012) indicate that environmental biases to selection can be substantial. Previous quantitative genetic tests in birds have been more equivocal (Sheldon et al. 2003; Gienapp et al. 2006) but based on two-step analyses of PBVs, which are known to be statistically unreliable (Postma 2006; Hadfield et al. 2010). Our analyses were based on a statistically robust, one-step animal model approach, as recommended by Hadfield 2008 (see also Morrissey et al. 2010) and recently applied by Robinson et al.(2008), by Morrissey and Ferguson (2011), by Morrissey et al. (2012) and by Tarka et al. (2015).

\section{Conclusions}

Our data show that potential for microevolution exists in this population and, crucially, that changing relationships between phenotypes and fitness are underpinned by changing selection on breeding values, which are both essential requirements for adaptive evolution in changing environments (Endler 1986). Future climate change is likely to lead to further directional selection on $L D$ in particular (Gienapp et al. 2014). While phenotypic plasticity will allow for adaptive tracking of environmental change to some extent (Charmantier et al. 2008; Vedder et al. 2013), microevolution will be crucial for long-term adaptation and population persistence (Visser 2008; Gienapp et al. 2013). The fact that selection acts on the genetic component of breeding time implies that evolution of $L D$ can track climate change, 
provided the pace of climate change remains within demographically tolerable limits (Gienapp et al. 2013). We cannot however rule out the possibility of small to moderate magnitude biases to selection estimates, and thus environmental change may lead to weaker (or stronger) selection on underlying breeding values than might be predicted based on phenotypic relationships alone. Missing traits were not a major problem in our selection analyses, as indicated by the concordance between predictions based on the STS and MVBE approaches, but it is worth noting that unmeasured phenotypes may themselves have a genetic basis and be targets of section in a changing environment. Combining inferences from quantitative genetic analyses with experimental tests of causality will allow for better forecasting of potential responses to environmental change. Finally, we note that feedbacks between ecology and evolution, or so-called 'eco-evolutionary dynamics', require that ecologically-induced phenotypic selection actually results in microevolutionary responses, which in turn requires that selection acts on the genotypic component of trait variation (as we have shown here) rather than simply on the environmental component. This reinforces the need to better understand how different types of ecological change alter the relationship between breeding values for key traits and fitness.

\section{Acknowledgements}

We thank Arild Husby and Michael Morrissey for valuable discussions. Jarrod Hadfield and three anonymous reviewers provided very useful criticisms of a previous draft. TER was supported by the Beaufort Marine Research Award in Fish Population Genetics funded by the Irish Government under the Sea Change Programme.

\section{References}


Both, C., J. M. Tinbergen, and M. E. Visser. 2000. Adaptive density dependence of avian clutch size. Ecology 81:3391-3403.

Bouwhuis, S., O. Vedder, C. J. Garroway, and B. C. Sheldon. 2015. Ecological causes of multilevel covariance between size and first-year survival in a wild bird population. J. Anim. Ecol. 84:208-218.

Brinkhof, M. W., A. J. Cavé, F. J. Hage, and S. Verhulst. 1993. Timing of reproduction and fledging success in the coot Fulica atra: evidence for a causal relationship. J. Anim. Ecol. $577-587$.

Burt, A. 1995. Perspective: the evolution of fitness. Evolution 49:1-8.

Carlson, S. M., C. J. Cunningham, and P. A. Westley. 2014. Evolutionary rescue in a changing world. Trends Ecol. Evol. 29:521-530.

Caro, S. P., A. Charmantier, M. M. Lambrechts, J. Blondel, J. Balthazart, and T. D. Williams. 2009. Local adaptation of timing of reproduction: females are in the driver's seat. Funct. Ecol. 23:172-179.

Charmantier, A., and P. Gienapp. 2014. Climate change and timing of avian breeding and migration: evolutionary versus plastic changes. Evol. Appl. 7:15-28.

Charmantier, A., R. H. McCleery, L. R. Cole, C. Perrins, L. E. Kruuk, and B. C. Sheldon. 2008. Adaptive phenotypic plasticity in response to climate change in a wild bird population. Science 320:800-803.

Chevin, L.-M., M. E. Visser, and J. Tufto. 2015. Estimating the variation, autocorrelation, and environmental sensitivity of phenotypic selection. Evolution 69:2319-2332.

Crow, J. F., and T. Nagylaki. 1976. The rate of change of a character correlated with fitness. Am. Nat. 110: 207-213. 
Daan, S., C. Dijkstra, and J. M. Tinbergen. 1990. Family planning in the kestrel (Falco tinnunculus): the ultimate control of covariation of laying date and clutch size. Behaviour 114:83-116.

Dijkstra, C., A. Bult, S. Bijlsma, S. Daan, T. Meijer, and M. Zijlstra. 1990. Brood size manipulations in the kestrel (Falco tinnunculus): effects on offspring and parent survival. J. Anim. Ecol. 269-285.

Endler, J. A. 1986. Natural selection in the wild. Princeton University Press, Princeton. Estes, S., and S. J. Arnold. 2007. Resolving the paradox of stasis: models with stabilizing selection explain evolutionary divergence on all timescales. Am. Nat. 169:227-244. Falconer, D. S., and T. F. C. Mackay. 1996. Introduction to Quantitative Genetics. Longman, London.

Fisher, R. A. 1958. The genetical theory of natural selection. 2nd ed. Dover, New York. Foulley, J. L. and Im, S. 1993. A marginal quasi-likelihood approach to the analysis of Poisson variables with generalized linear mixed models. Genet. Sel. Evol. 23: 101-107. Garant, D., J. D. Hadfield, L. E. Kruuk, and B. C. Sheldon. 2008. Stability of genetic variance and covariance for reproductive characters in the face of climate change in a wild bird population. Mol. Ecol. 17:179-188.

Gienapp, P., M. Lof, T. E. Reed, J. McNamara, S. Verhulst, and M. E. Visser. 2013. Predicting demographically sustainable rates of adaptation: can great tit breeding time keep pace with climate change? Philos. Trans. R. Soc. B Biol. Sci. 368:20120289.

Gienapp, P., E. Postma, and M. E. Visser. 2006. Why breeding time has not responded to selection for earlier breeding in a songbird population. Evolution 60:2381-2388.

Gienapp, P., T. E. Reed, and M. E. Visser. 2014. Why climate change will invariably alter selection pressures on phenology. Proc. R. Soc. B Biol. Sci. 281:20141611. 
Gomulkiewicz, R., and R. D. Holt. 1995. When does evolution by natural selection prevent extinction? Evolution 49: 201-207.

Gonzalez, A., O. Ronce, R. Ferriere, and M. E. Hochberg. 2013. Evolutionary rescue: an emerging focus at the intersection between ecology and evolution. Philos. Trans. R. Soc. B Biol. Sci. 368:20120404.

Hadfield, J. D. 2010. MCMC methods for multi-response generalized linear mixed models: the MCMCglmm R package. J. Stat. Softw. 33:1-22.

Hadfield, J. D., A. J. Wilson, D. Garant, B. C. Sheldon, and L. E. Kruuk. 2010. The misuse of BLUP in ecology and evolution. Am. Nat. 175:116-125.

Holt, R. D. 1990. The microevolutionary consequences of climate change. Trends Ecol. Evol. $5: 311-315$.

Husby, A., D. H. Nussey, M. E. Visser, A. J. Wilson, B. C. Sheldon, and L. E. Kruuk. 2010. Contrasting patterns of phenotypic plasticity in reproductive traits in two great tit (Parus major) populations. Evolution 64:2221-2237.

Kruuk, L. E. 2004. Estimating genetic parameters in natural populations using the "animal model.” Philos. Trans. R. Soc. Lond. B. Biol. Sci. 359:873-890.

Kruuk, L. E., J. Merilä, and B. C. Sheldon. 2001. Phenotypic selection on a heritable size trait revisited. Am. Nat. 158:557-571.

Kruuk, L. E., J. Merilä, and B. C. Sheldon. 2003. When environmental variation shortcircuits natural selection. Trends Ecol. Evol. 18:207-209.

Kruuk, L. E., J. Slate, J. M. Pemberton, S. Brotherstone, F. Guinness, and T. Clutton-Brock. 2002. Antler size in red deer: heritability and selection but no evolution. Evolution 56:16831695.

Lande, R. 1976. Natural selection and random genetic drift in phenotypic evolution. Evolution 30: 314-334. 
Lande, R., and S. J. Arnold. 1983. The measurement of selection on correlated characters. Evolution 37: 1210-1226.

Lynch, M., and B. Walsh. 1998. Genetics and Analysis of Quantitative Traits. 1st ed. Sinauer Associates, Incorporated, Sunderland.

MacColl, A. D. 2011. The ecological causes of evolution. Trends Ecol. Evol. 26:514-522.

Merilä, J., B. C. Sheldon, and L. E. B. Kruuk. 2001. Explaining stasis: microevolutionary studies in natural populations. Genetica 112:199-222

Monaghan, P., and R. G. Nager. 1997. Why don't birds lay more eggs? Trends Ecol. Evol. $12: 270-274$.

Morrissey, M. B., P. de Villemereuil, B. Doligez, and O. Gimenez. 2014. Bayesian approaches to the quantitative genetic analysis of natural populations. In: Charmantier A, Garant D and Kruuk LEB, editors. Quantitative Genetics in the Wild. Oxford University Press, Oxford, UK. pp. 228-253.

Morrissey, M. B., and M. M. Ferguson. 2011. A test for the genetic basis of natural selection: an individual-based longitudinal study in a stream-dwelling fish. Evolution 65:1037-1047. Morrissey, M. B., L. E. B. Kruuk, and A. J. Wilson. 2010. The danger of applying the breeder's equation in observational studies of natural populations. J. Evol. Biol. 23:22772288.

Morrissey, M. B., D. J. Parker, P. Korsten, J. M. Pemberton, L. E. Kruuk, and A. J. Wilson. 2012. The prediction of adaptive evolution: empirical application of the secondary theorem of selection and comparison to the breeder's equation. Evolution 66:2399-2410.

Nager, R. G., C. Ruegger, and A. J. Van Noordwijk. 1997. Nutrient or energy limitation on egg formation: a feeding experiment in great tits. J. Anim. Ecol. 495-507.

Nur, N. 1987. Alternative reproductive tactics in birds: individual variation in clutch size. Pp. 49-77 in Perspectives in ethology. Springer. 
Pettifor, R. A., C. M. Perrins, and R. H. McCleery. 1988. Individual optimization of clutch size in great tits. Nature 336:160-162.

Postma, E., and A. J. van Noordwijk. 2005. Gene flow maintains a large genetic difference in clutch size at a small spatial scale. Nature 433:65-68.

Postma, E. 2006. Implications of the difference between true and predicted breeding values for the study of natural selection and micro-evolution. J. Evol. Biol. 19:309-320.

Postma, E., J. Visser, and A. J. Van Noordwijk. 2007. Strong artificial selection in the wild results in predicted small evolutionary change. J. Evol. Biol. 20:1823-1832.

Price, G. R. 1970. Selection and covariance. Nature 227:520-21.

Price, T., M. Kirkpatrick, and S. J. Arnold. 1988. Directional selection and the evolution of breeding date in birds. Science(Washington) 240:798-799.

Rausher, M. D. 1992. The measurement of selection on quantitative traits: biases due to environmental covariances between traits and fitness. Evolution 46:616-626.

Reed, T. E., S. Jenouvrier, and M. E. Visser. 2013. Phenological mismatch strongly affects individual fitness but not population demography in a woodland passerine. J. Anim. Ecol. $82: 131-144$.

Robertson, A. 1966. A mathematical model of the culling process in dairy cattle. Anim. Prod. 8:95-108.

Robinson, M. R., J. G. Pilkington, T. H. Clutton-Brock, J. M. Pemberton, and L. E. Kruuk. 2008. Environmental heterogeneity generates fluctuating selection on a secondary sexual trait. Curr. Biol. 18:751-757.

Sæther, B.-E., Visser, M.A., Grøtan, V., and Engen, S. In Press. Evidence for r- and Kselection in a wild bird population: a reciprocal link between ecology and evolution. Proc. R. Soc. Lond. B Biol. Sci. 
Scheiner, S. M., K. Donohue, L. A. Dorn, S. J. Mazer, and L. M. Wolfe. 2002. Reducing environmental bias when measuring natural selection. Evolution 56:2156-2167.

Schluter, D. 1996. Adaptive radiation along genetic lines of least resistance. Evolution 17661774

Sheldon, B. C., L. E. B. Kruuk, and J. Merila. 2003. Natural selection and inheritance of breeding time and clutch size in the collared flycatcher. Evolution 57:406-420.

Smouse, P. E., T. R. Meagher, and C. J. Kobak. 1999. Parentage analysis in Chamaelirium luteum (L.) Gray (Liliaceae): why do some males have higher reproductive contributions? J. Evol. Biol. 12:1069-1077.

Stinchcombe, J. R., M. T. Rutter, D. S. Burdick, P. Tiffin, M. D. Rausher, and R. Mauricio. 2002. Testing for environmentally induced bias in phenotypic estimates of natural selection: theory and practice. Am. Nat. 160:511-523.

Stinchcombe, J. R., A. K. Simonsen, and M. Blows. 2014. Estimating uncertainty in multivariate responses to selection. Evolution 68:1188-1196.

Svensson, E. 1997. Natural selection on avian breeding time: causality, fecundity-dependent, and fecundity-independent selection. Evolution 1276-1283.

Tarka, M., B. Hansson, and D. Hasselquist. 2015. Selection and evolutionary potential of spring arrival phenology in males and females of a migratory songbird. J. Evol. Biol. 5: $1024-1038$.

Tinbergen, J. M., and C. Both. 1999. Is clutch size individually optimized? Behav. Ecol. 10:504-509.

Vedder, O., S. Bouwhuis, and B. C. Sheldon. 2013. Quantitative assessment of the importance of phenotypic plasticity in adaptation to climate change in wild bird populations. PLoS Biol. 11:e1001605. 
Verhulst, S., and J. M. Tinbergen. 1991. Experimental evidence for a causal relationship between timing and success of reproduction in the great tit Parus m. major. J. Anim. Ecol. $269-282$.

Verhulst, S., and J.-Å. Nilsson. 2008. The timing of birds' breeding seasons: a review of experiments that manipulated timing of breeding. Philos. Trans. R. Soc. B Biol. Sci. 363:399-410.

Visser, M. E., and C. M. Lessells. 2001. The costs of egg production and incubation in great tits (Parus major). Proc. R. Soc. Lond. B Biol. Sci. 268:1271-1277.

Visser, M. E. 2008. Keeping up with a warming world; assessing the rate of adaptation to climate change. Proc. R. Soc. B Biol. Sci. 275:649-659.

Visser, M. E., L. J. Holleman, and P. Gienapp. 2006. Shifts in caterpillar biomass phenology due to climate change and its impact on the breeding biology of an insectivorous bird. Oecologia 147:164-172.

Visser, M. E., A. J. Van Noordwijk, J. M. Tinbergen, and C. M. Lessells. 1998. Warmer springs lead to mistimed reproduction in great tits (Parus major). Proc. R. Soc. Lond. B Biol. Sci. 265:1867-1870.

Walsh, B., and M. W. Blows. 2009. Abundant genetic variation+ strong selection= multivariate genetic constraints: a geometric view of adaptation. Annu. Rev. Ecol. Evol. Syst. 40:41-59.

Wilson, A. J. 2008. Why h2 does not always equal VA/VP? J. Evol. Biol. 21:647-650.

Wilson, A. J., D. Réale, M. N. Clements, M. M. Morrissey, E. Postma, C. A. Walling, L. E. B. Kruuk, and D. H. Nussey. 2010. An ecologist's guide to the animal model. J. Anim. Ecol. $79: 13-26$. 


\section{Figure legends:}

Fig.1 Schematic of hypothetical relationships between trait and fitness at the genetic (filled circles, solid lines in insets) and environmental levels (open circles, dashed lines in insets). Each panel corresponds to a different scenario of environmental bias (quantified as $\beta_{E}-\beta_{G}$ ), with three different strengths of phenotypic selection (overall relationship between trait and fitness at phenotypic level) shown in each.

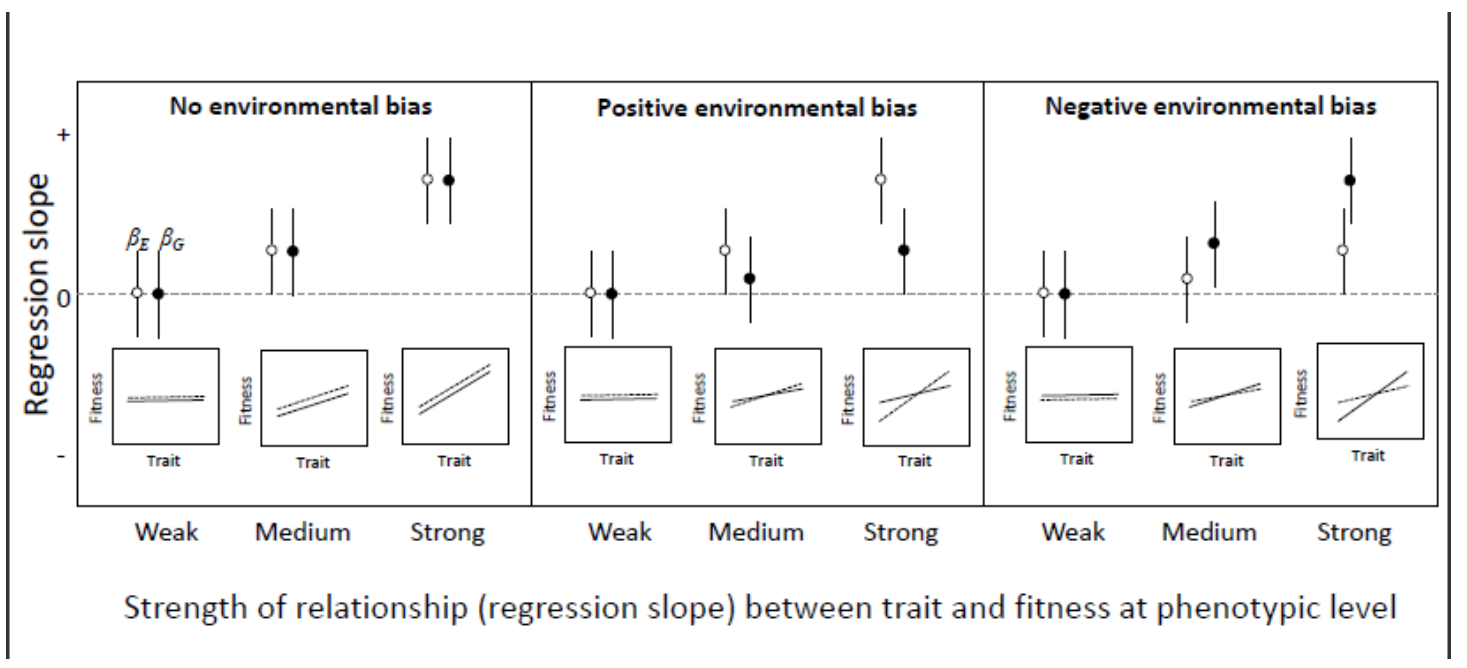

Fig.2 Relationships between trait and fitness, measured as standardised selection gradients, at the genetic ( $\beta_{G}$, filled circles) versus environmental level ( $\beta_{E}$, open circles) for years with weak, medium and strong phenotypic selection on each trait in each study population. Shown are posterior modes \pm highest posterior density intervals. 


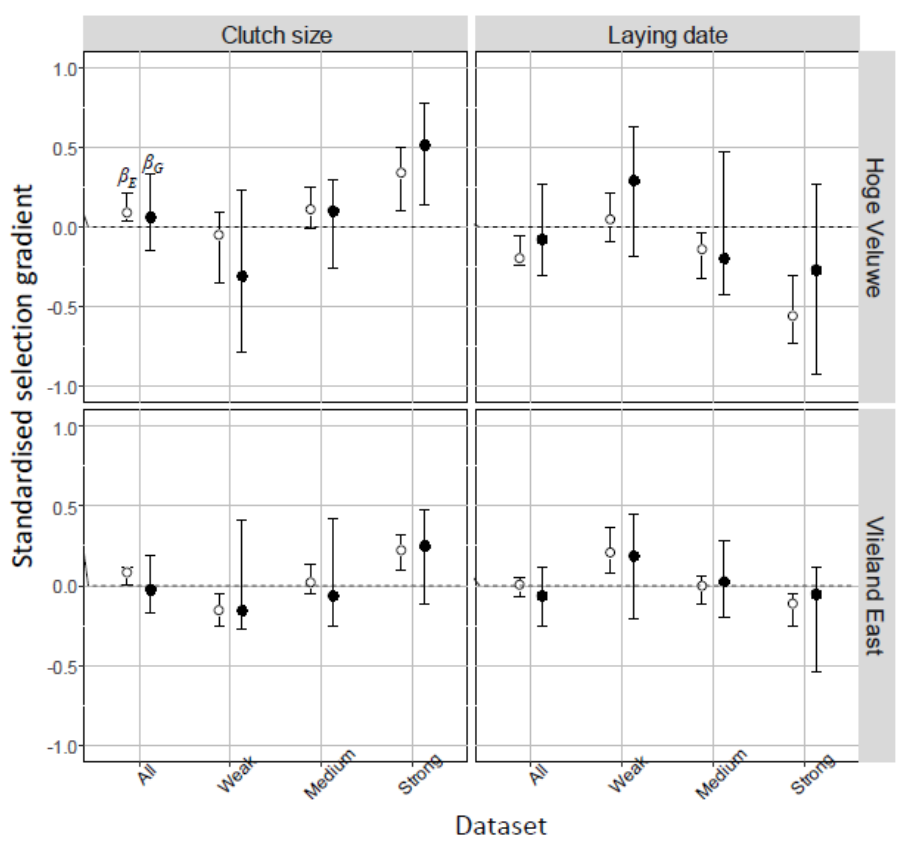

Fig. 3 Power analysis results. Filled circles and solid line: HV population. Open circles and dashed line: VE population.

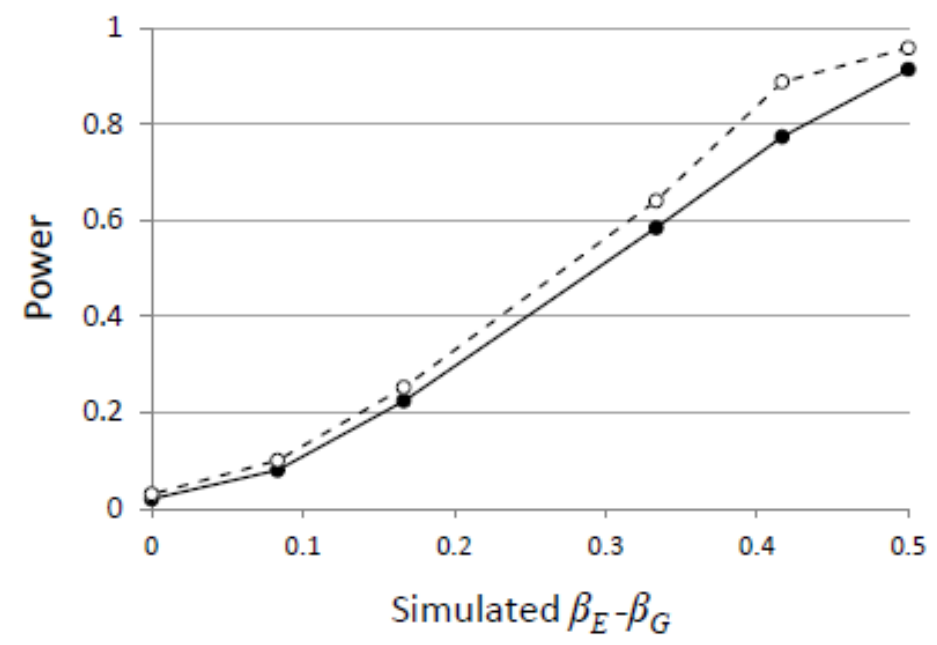

Fig.4 Comparing predictions of responses to selection based on the secondary theorem of selection (STS, grey bars) and multivariate breeder's equation (MVBE, black bars) 
approaches. Units are phenotypic standard deviations. See main text for explanation of error bars.
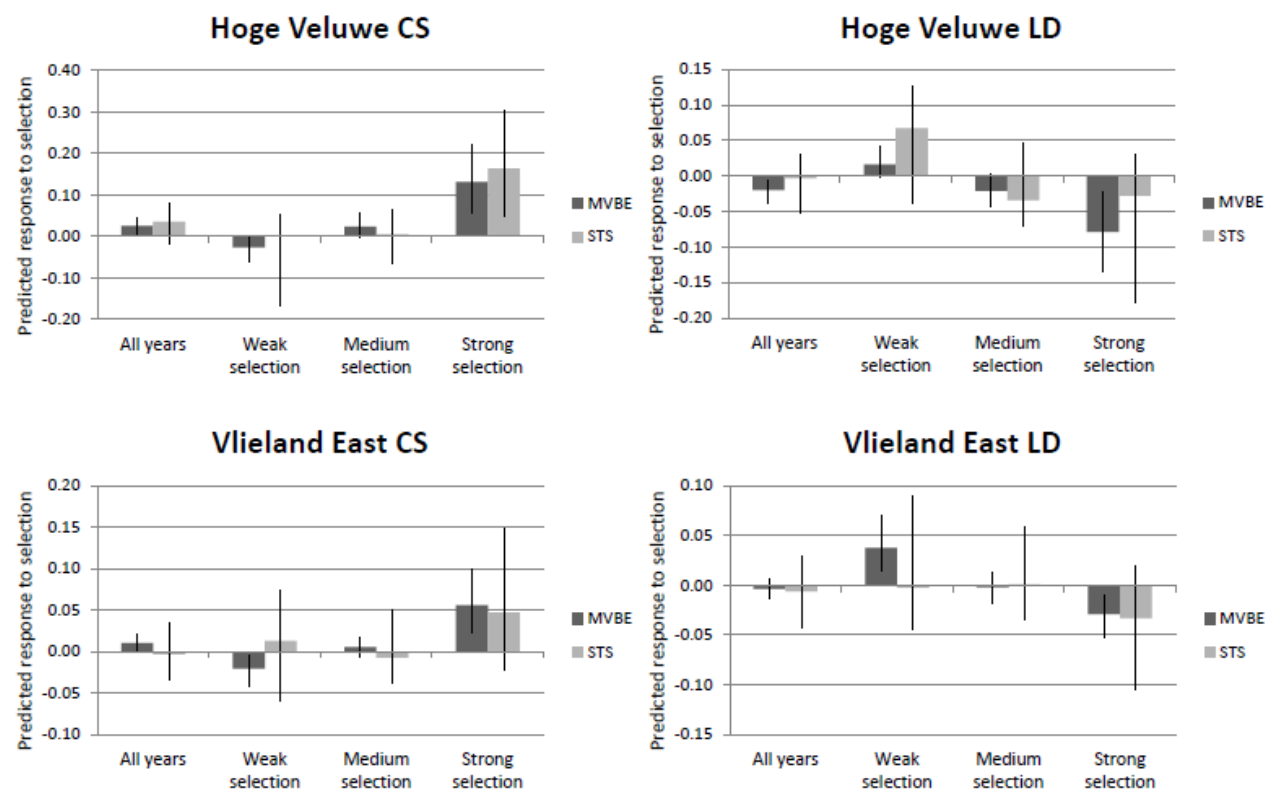

Table 1: Datasets analysed and associated sample sizes. For both study areas, years were split into groups according to variation in standardised phenotypic selection differentials $\left(s_{P}\right)$ for laying date and clutch size. 'N records' refers to the number of first clutches monitored. 'N females' refers to the number of uniquely marked individual females producing those clutches (some females breed in multiple years).

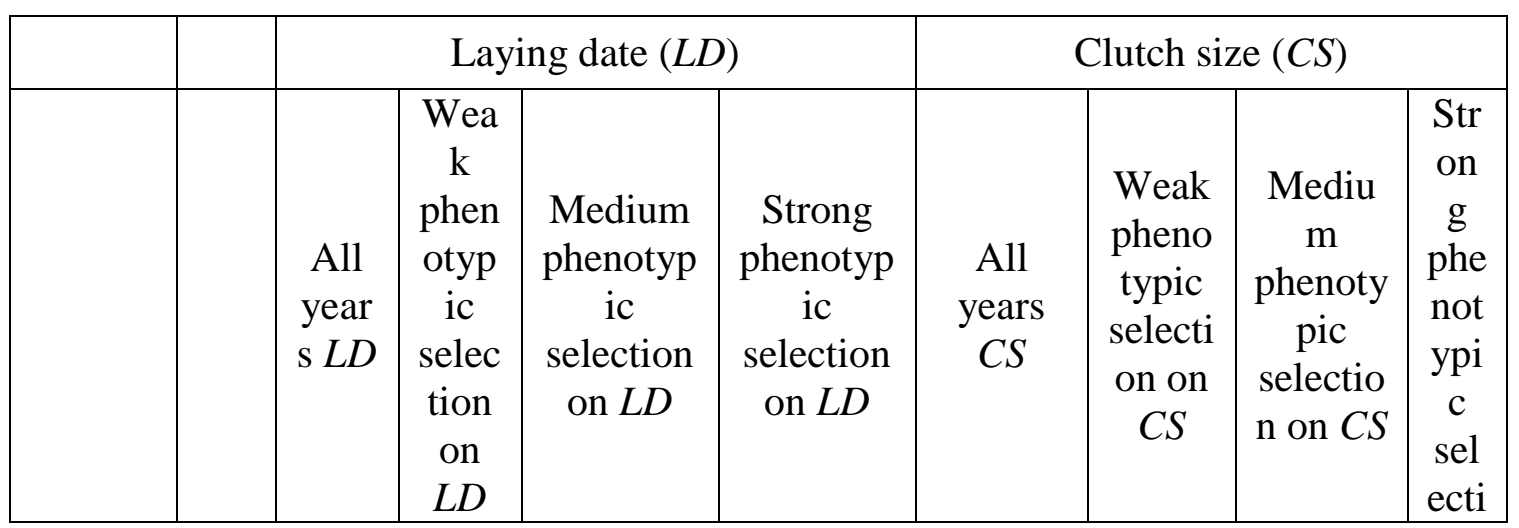




\begin{tabular}{|c|c|c|c|c|c|c|c|c|c|}
\hline & & & & & & & & & $\begin{array}{l}\text { on } \\
\text { on } \\
C S\end{array}$ \\
\hline \multirow[t]{6}{*}{$\begin{array}{l}\text { Hoge } \\
\text { Veluw } \\
\text { e }\end{array}$} & $\begin{array}{l}\mathrm{N} \\
\text { yea } \\
\text { rs } \\
\end{array}$ & 59 & 20 & 19 & 20 & 59 & 20 & 19 & 20 \\
\hline & $\begin{array}{l}\mathrm{N} \\
\text { rec } \\
\text { ord } \\
\mathrm{S}\end{array}$ & 4062 & 1333 & 1642 & 1087 & 4062 & 1271 & 1500 & $\begin{array}{l}12 \\
91\end{array}$ \\
\hline & $\begin{array}{l}\mathrm{N} \\
\mathrm{fe} \\
\mathrm{ma} \\
\text { les }\end{array}$ & 2871 & 1186 & 1414 & 960 & 2871 & 1154 & 1238 & $\begin{array}{l}10 \\
93\end{array}$ \\
\hline & $\begin{array}{l}\mathrm{Me} \\
\text { an } \\
s_{P}\end{array}$ & 0.14 & 0.17 & -0.22 & -0.55 & 0.16 & -0.16 & 0.12 & $\begin{array}{c}0.4 \\
6\end{array}$ \\
\hline & $\begin{array}{l}\mathrm{Mi} \\
\mathrm{n} \\
s_{P}\end{array}$ & $\begin{array}{c}- \\
1.06\end{array}$ & $\begin{array}{c}- \\
0.05\end{array}$ & -0.34 & -1.06 & -0.68 & -0.68 & 0.03 & $\begin{array}{c}0.2 \\
5\end{array}$ \\
\hline & $\begin{array}{l}\mathrm{Ma} \\
\mathrm{X} \\
s_{P} \\
\end{array}$ & 0.98 & 0.98 & -0.07 & -0.36 & 0.69 & 0.01 & 0.24 & $\begin{array}{c}0.6 \\
9\end{array}$ \\
\hline \multirow[t]{6}{*}{$\begin{array}{l}\text { Vlielan } \\
\text { d East }\end{array}$} & $\begin{array}{l}\mathrm{N} \\
\text { yea } \\
\text { rs }\end{array}$ & 51 & 17 & 17 & 17 & 51 & 17 & 17 & 17 \\
\hline & $\begin{array}{l}\mathrm{N} \\
\text { rec } \\
\text { ord } \\
\mathrm{S}\end{array}$ & 2714 & 504 & 1373 & 837 & 2714 & 863 & 977 & $\begin{array}{c}87 \\
4\end{array}$ \\
\hline & $\begin{array}{l}\mathrm{N} \\
\mathrm{fe} \\
\mathrm{ma} \\
\text { les }\end{array}$ & 1663 & 439 & 1030 & 763 & 1663 & 747 & 807 & $\begin{array}{c}72 \\
9\end{array}$ \\
\hline & $\begin{array}{l}\mathrm{Me} \\
\text { an } \\
s_{P} \\
\end{array}$ & $\begin{array}{c}- \\
0.00 \\
4 \\
\end{array}$ & 0.29 & -0.02 & -0.28 & 0.02 & -0.24 & 0.05 & $\begin{array}{c}0.2 \\
6\end{array}$ \\
\hline & $\begin{array}{l}\mathrm{Mi} \\
\mathrm{n} \\
s_{P} \\
\end{array}$ & $\begin{array}{c}- \\
0.86\end{array}$ & 0.08 & -0.11 & -0.86 & -0.72 & -0.72 & -0.01 & $\begin{array}{c}0.1 \\
4\end{array}$ \\
\hline & $\begin{array}{l}\mathrm{Ma} \\
\mathrm{X} \\
s_{P} \\
\end{array}$ & 0.64 & 0.64 & 0.06 & -0.13 & 0.48 & -0.02 & 0.14 & $\begin{array}{c}0.4 \\
8\end{array}$ \\
\hline
\end{tabular}


Table 2: Estimates of the extent of environmental bias to selection $\left(\beta_{E-} \beta_{G}\right)$ based on the trivariate animal models. $\mathrm{PS}=$ phenotypic selection. $\beta_{G}=$ genetic selection gradient. $\beta_{E}=$ environmental selection gradient. Mode $=$ mode of posterior distribution. $\mathrm{LCI} / \mathrm{UCI}=$ lower/upper highest posterior density intervals.

\begin{tabular}{|c|c|c|c|c|c|c|c|c|c|c|c|}
\hline $\begin{array}{l}\text { Study } \\
\text { area }\end{array}$ & Trait & $\begin{array}{l}\text { Datase } \\
\mathrm{t}\end{array}$ & $\begin{array}{l}\boldsymbol{\beta}_{E}- \\
\boldsymbol{\beta}_{G} \\
(\bmod \\
\text { e) }\end{array}$ & $\begin{array}{l}\boldsymbol{\beta}_{E}- \\
\boldsymbol{\beta}_{G} \\
(\mathbf{L C I} \\
)\end{array}$ & $\begin{array}{l}\boldsymbol{\beta}_{E^{-}} \\
\boldsymbol{\beta}_{G} \\
(\mathbf{U C I} \\
)\end{array}$ & $\begin{array}{l}\beta_{G} \\
(\bmod \\
\text { e) }\end{array}$ & $\begin{array}{l}\boldsymbol{\beta}_{G} \\
(\mathbf{L C I} \\
)\end{array}$ & $\begin{array}{l}\boldsymbol{\beta}_{G} \\
(\mathbf{U} \\
\mathbf{C I} \\
)\end{array}$ & $\begin{array}{l}\beta_{E} \\
(\mathbf{m} \\
\text { ode } \\
\text { ) }\end{array}$ & $\begin{array}{l}\boldsymbol{\beta}_{E} \\
(\mathbf{L} \\
\mathbf{C I})\end{array}$ & $\begin{array}{l}\boldsymbol{\beta}_{E} \\
(\mathbf{U} \\
\mathbf{C I})\end{array}$ \\
\hline \multirow{8}{*}{$\begin{array}{l}\text { Hoge } \\
\text { Veluw } \\
\text { e }\end{array}$} & $\begin{array}{l}\text { Clutc } \\
\text { h size }\end{array}$ & $\begin{array}{l}\text { All } \\
\text { years }\end{array}$ & 0.01 & -0.24 & 0.32 & 0.06 & -0.15 & $\begin{array}{l}0.3 \\
3\end{array}$ & $\begin{array}{l}0.0 \\
9\end{array}$ & $\begin{array}{l}0.0 \\
4\end{array}$ & $\begin{array}{l}0.2 \\
1\end{array}$ \\
\hline & & $\begin{array}{l}\text { Weak } \\
\text { PS }\end{array}$ & -0.13 & -0.42 & 0.74 & -0.31 & -0.78 & $\begin{array}{l}0.2 \\
3\end{array}$ & $\begin{array}{l}- \\
0.0 \\
5\end{array}$ & $\begin{array}{l}- \\
0.3 \\
5\end{array}$ & $\begin{array}{l}0.0 \\
9\end{array}$ \\
\hline & & $\begin{array}{l}\text { Mediu } \\
\text { m PS }\end{array}$ & -0.01 & -0.23 & 0.46 & 0.10 & -0.26 & $\begin{array}{l}0.2 \\
9\end{array}$ & $\begin{array}{l}0.1 \\
1\end{array}$ & $\begin{array}{l}- \\
0.0 \\
1\end{array}$ & $\begin{array}{l}0.2 \\
5\end{array}$ \\
\hline & & $\begin{array}{l}\text { Strong } \\
\text { PS }\end{array}$ & -0.21 & -0.59 & 0.26 & 0.51 & 0.14 & $\begin{array}{l}0.7 \\
7\end{array}$ & $\begin{array}{l}0.3 \\
4\end{array}$ & $\begin{array}{l}0.1 \\
0\end{array}$ & $\begin{array}{l}0.5 \\
0\end{array}$ \\
\hline & $\begin{array}{l}\text { Layin } \\
\text { g date }\end{array}$ & $\begin{array}{l}\text { All } \\
\text { years }\end{array}$ & -0.03 & -0.46 & 0.21 & -0.08 & -0.31 & $\begin{array}{l}0.2 \\
6\end{array}$ & $\begin{array}{l}- \\
0.2 \\
0\end{array}$ & $\begin{array}{l}- \\
0.2 \\
4\end{array}$ & $\begin{array}{l}- \\
0.0 \\
6\end{array}$ \\
\hline & & $\begin{array}{l}\text { Weak } \\
\text { PS }\end{array}$ & -0.09 & -0.59 & 0.42 & 0.29 & -0.18 & $\begin{array}{l}0.6 \\
3\end{array}$ & $\begin{array}{l}0.0 \\
5\end{array}$ & $\begin{array}{l}- \\
0.0 \\
9\end{array}$ & $\begin{array}{l}0.2 \\
1\end{array}$ \\
\hline & & $\begin{array}{l}\text { Mediu } \\
\text { m PS }\end{array}$ & 0.02 & -0.59 & 0.43 & -0.20 & -0.43 & $\begin{array}{l}0.4 \\
7\end{array}$ & $\begin{array}{l}- \\
0.1 \\
4\end{array}$ & $\begin{array}{l}- \\
0.3 \\
2\end{array}$ & $\begin{array}{l}- \\
0.0 \\
4\end{array}$ \\
\hline & & $\begin{array}{l}\text { Strong } \\
\text { PS }\end{array}$ & -0.26 & -0.92 & 0.49 & -0.27 & -0.92 & $\begin{array}{l}0.2 \\
6\end{array}$ & $\begin{array}{l}- \\
0.5 \\
6\end{array}$ & $\begin{array}{l}- \\
0.7 \\
3\end{array}$ & $\begin{array}{l}- \\
0.3 \\
1\end{array}$ \\
\hline \multirow[t]{7}{*}{$\begin{array}{l}\text { Vlielan } \\
\text { d East }\end{array}$} & $\begin{array}{l}\text { Clutc } \\
\text { h size }\end{array}$ & $\begin{array}{l}\text { All } \\
\text { years }\end{array}$ & 0.11 & -0.14 & 0.27 & -0.02 & -0.17 & $\begin{array}{l}0.1 \\
9\end{array}$ & $\begin{array}{l}0.0 \\
8\end{array}$ & $\begin{array}{l}0.0 \\
1\end{array}$ & $\begin{array}{l}0.1 \\
2\end{array}$ \\
\hline & & $\begin{array}{l}\text { Weak } \\
\text { PS }\end{array}$ & -0.22 & -0.57 & 0.23 & -0.15 & -0.27 & $\begin{array}{l}0.4 \\
1\end{array}$ & $\begin{array}{l}- \\
0.1 \\
5\end{array}$ & $\begin{array}{l}- \\
0.2 \\
5\end{array}$ & $\begin{array}{l}- \\
0.0 \\
5\end{array}$ \\
\hline & & $\begin{array}{l}\text { Mediu } \\
\text { m PS }\end{array}$ & 0.10 & -0.42 & 0.32 & -0.06 & -0.26 & $\begin{array}{l}0.4 \\
2\end{array}$ & $\begin{array}{l}0.0 \\
2\end{array}$ & $\begin{array}{l}- \\
0.0 \\
5\end{array}$ & $\begin{array}{l}0.1 \\
3\end{array}$ \\
\hline & & $\begin{array}{l}\text { Strong } \\
\text { PS }\end{array}$ & 0.07 & -0.24 & 0.46 & 0.25 & -0.12 & $\begin{array}{l}0.4 \\
7\end{array}$ & $\begin{array}{l}0.2 \\
2\end{array}$ & $\begin{array}{l}0.1 \\
0\end{array}$ & $\begin{array}{l}0.3 \\
2\end{array}$ \\
\hline & $\begin{array}{l}\text { Layin } \\
\text { g date }\end{array}$ & $\begin{array}{l}\text { All } \\
\text { years }\end{array}$ & -0.01 & -0.20 & 0.24 & -0.06 & -0.26 & $\begin{array}{l}0.1 \\
2\end{array}$ & $\begin{array}{l}0.0 \\
1\end{array}$ & $\begin{array}{l}- \\
0.0 \\
7\end{array}$ & $\begin{array}{l}0.0 \\
5\end{array}$ \\
\hline & & $\begin{array}{l}\text { Weak } \\
\text { PS }\end{array}$ & 0.17 & -0.33 & 0.44 & 0.19 & -0.21 & $\begin{array}{l}0.4 \\
5 \\
\end{array}$ & $\begin{array}{l}0.2 \\
1 \\
\end{array}$ & $\begin{array}{l}0.0 \\
8 \\
\end{array}$ & $\begin{array}{l}0.3 \\
6 \\
\end{array}$ \\
\hline & & Mediu & -0.02 & -0.38 & 0.21 & 0.03 & -0.20 & 0.2 & 0.0 & - & 0.0 \\
\hline
\end{tabular}




\begin{tabular}{|l|l|l|l|l|l|l|l|l|l|l|l|}
\hline & m PS & & & & & & 8 & 0 & 0.1 & 6 \\
2 & \\
\hline & Strong & -0.05 & -0.29 & 0.45 & -0.05 & -0.54 & 0.1 & - & - & - \\
2 & & & & & & & 2 & 0.1 & 0.2 & 0.0 \\
5
\end{tabular}

